\title{
Online Course with Use of Free Online Learning Materials
}

\author{
Rudolf Burgi \\ University of Maryland University College (UMUC), Adelphi, MD, USA \\ rburgi@faculty.umuc.edu
}

Keywords: learning material; free internet resource; class overview; class introduction; decision making; online learning; online course; UMUC.

\begin{abstract}
Course resources can be a costly part of studying. Today's internet provides a huge collection of learning materials available for class use. The University of Maryland University College started to use free learning materials from the internet to replace costly commercial course resources. The use of free internet resources has to be managed, so that they support the course without negative side effects. The use of a course introduction and overview helps the students relate the internet resources to the course topics. The "Introduction to Decision Making - A Short Overview” is presented as an example.
\end{abstract}

\section{Introduction}

Online courses have a long history. Forerunners of online courses were distance education through the mail, correspondence courses, audio and visual training through radio and television, and use of satellite TV. In the early 1960s, as computers became more common, computer assisted learning was developed [1]. In the late 1980s, when the internet started to become prominent, more and more education providers began to use it for providing online courses [2]-[5]. A further step was tele-learning, a main focus of the IEEE Communications Magazine in March 1999 [6].

Besides building the foundation for online classes, the internet developed into a huge collection of learning, useful in many ways. Today at the University of Maryland University College (UMUC) the internet is being used to provide free instructional materials for the course offerings.

\section{Classes at the University of Maryland University College School of Undergraduate Studies}

Up until a few years ago, the UMUC School of Undergraduate Studies (SUS) used to provide courses in three formats: There were the traditional on-site courses provided to local students in a class room, the online courses provided to students with internet access, and the so-called hybrid courses with a mix of on-site and online work throughout the semester. Now, as the undergraduate courses are given in a condensed 8-week-format, all classes are either in online or hybrid format.

2.1. Online Learning at the University of Maryland University College. In 1994, UMUC introduced Tycho, a software developed by SUS instructional technology. Tycho replaced earlier online learning tools which were run on VAX machines, it was upgraded several times before being replaced as WebTycho [7] by the actual Learning Experience Online (LEO) in fall of 2014. LEO is the learning environment of Desire to learn (D2L), which is being used in all UMUC classes [8].

2.2. Online Class Description. Classes at SUS are characterized by their limited class size of at most 32 students with a correspondingly good student support through the instructors.

Class work includes 8 weeks of class discussions on LEO and several individual assignments. In addition, there can be other graded items like quizzes or tests. The students can also be grouped for group assignments. Quizzes, surveys, and self-assessments can be used as additional class tools.

An initiative at UMUC works on reducing the costs for students. Starting in 2015 all classes with only a few exceptions use free learning materials, mostly electronic and online class materials instead of textbooks. The class materials are mostly from the internet. They are selected to meet the course requirements and represent the latest industry information [9]. Beginning in the fall semester 
of 2016 UMUC will also replace most textbooks with electronic materials for its graduate courses. Aside from the lower cost to the students, by using these free resources, it is easier to include special course topics as desired, as long as the corresponding free internet material is available.

\section{Free Internet Resources Used for Online Classes}

All types of resources available on the internet can be used for online Courses. The most prevalent resources include:

- Electronic text books;

- Lectures;
- Documents;

- Videos;
- News reports;

- Web Log posts.

Usually there are many good and free resources available, but not all sources provide the same quality. For academic use, the sources should be trustworthy; therefore the following providers should be checked for materials first:

- (other) Universities;

- Special-topic web sites;
- Professional organizations;

- Professional publications;
- Governments;

- Newspapers.

Providers that do not host their material in a consistent way should be avoided and used only as a last resort. The presentation and format of some web sites is not optimal for study use. They are not easily downloaded or they do not print out nicely for offline use. Usually contents in Portable Document Format are well suited for offline class use. If everything else fails, copying the selected web contents to a word processor file allows for easy printout and offline use.

The redistribution of downloaded resources is not allowed for copyright reasons, so the original web links have to be provided to the students. While most internet resources can be accessed everywhere, some web sites are not available in some countries, so that students from these countries should be provided with alternative access possibilities.

\section{Setting up Online Classes with All-Free Resources}

The course authors have to define the course framework which defines and organizes the topics to be covered so that the students see an organized and complete picture of their course. To use the available resources more freely, it can help to use a short introduction to the course, giving all the aspects in a concise format. The weekly class sessions can develop the course topics in an organized manner based on this introduction.

4.1. Using Free Resources at the University of Maryland University College. Usually there are no complete textbooks available on the internet, but sometimes complete book chapters can be found and used. Resources have to be made available to cover all aspects of each topic, often several complementary resources are needed to completely cover a topic. Multiple resources often contradict one another, which can be very inspiring for the class discussions but it also can be confusing for the students of an introductory undergraduate class. Therefore a short introduction and overview can be used as study framework. An example of such an introduction is given in the appendix.

4.2. Problems with Online Resources. Internet resources pose problems similar to the problems of changing editions of text books. If the resource provider does not assure persistence of his web resources, these resources can suddenly disappear and no longer be found at their published location. The information can sometimes be found again in other web locations or alternative sources have to be searched for.

4.3. Handling and Managing a Class. Before every class, the web links have to be checked for their continued validity. If there are changes in the internet locations where resources are found, the web links have to be corrected. If a resource disappeared completely during a class or between two classes, replacement materials have to substitute the lost resource. Web search engines are a useful tool in finding free alternative resources. 


\section{Applicability to Other Courses}

The internet provides ample and useful English language resources. Additional materials should be produced and published on the internet. A course-specific introduction and overview similar to the one in the appendix should be provided for every course.

\section{References}

[1] H. R. Martens and R. W. Snelsire, A computer-oriented undergraduate systems course, in IEEE Trans. on Industrial Electronics and Control Instruments (IECI-13)1, 48-52, 1966.

[2] D.E. Zimmermann and M. Palmquist, Enhancing electrical engineering students' communication skills using online and hypertext aids, in IPCC 93 Proceedings, 428-431, 1993.

[3] D.M. Etter, G. C. Orsak and D.H. Johnson, A distance learning laboratory design experiment in undergraduate digital signal processing, in ICASSP-95 (5) 2885-2887, 1995.

[4] S. Rosenbaum, Communication as product: online courseware, in IPCC '91 Proceedings (1) 6064, 1991.

[5] P.K. Wiesner, Meeting educational needs through electronic delivery systems, in Southcon/94 Conference Record, 203-206, 1994.

[6] M.J. Finley, Tele-learning: The “Killer App”? IEEE Communications Magazine (37)3, 80-81.

[7] K. Harvett, C. Whitesel, E. Bank, R. Daumit, N. Calloway, W. Precht and B. Morris, The history of WebTycho, in Achiever, The alumni magazine of University of Maryland University College (Spring 2003) 14-17, 2003.

[8] UMUC, Learning Experience Online (LEO), [Online]. Available: http://www.umuc.edu/students/leo/

[9] UMUC, Textbooks and course materials, [Online]. Available: http://www.umuc.edu/students/support/coursematerials.cfm

\section{Appendix}

\section{Introduction to Decision Making - A Short Overview}

There is no human activity that does not involve decision making. While some decisions are made deliberately, others are made intuitively.

\section{A1. In the Undergraduate Course of Decision Making the Aspects of Deciding Can Be Looked at From Various Points of View}

- Process: Clarify the issue to be decided; work through the decision process; prepare for the decision; make the decision; implement the decision; review the decision outcomes.

- Timing: deciding instantaneously, delaying the decision to the latest possible moment to take advantage of the newest information.

- The decision making circumstances: Individual decision maker, another person making the decision, a group of people as decision makers, organizations as decision makers.

- Stakeholders: Decision maker, affected individuals, affected organizations, the public, customers, suppliers, governments.

- Influences on decision making: Biases; state of mind; economic, political, family, and religious situation, circumstances and dependencies. 
- Methods: Process, tools, analysis, alternatives, value calculation, decision tree.

- Drivers: Gut feeling, intuition, critical thinking, formal education, experience.

A beginner's decision making course should cover the bulk of decision making situations without generating too much complexity. Therefore, the following four areas are covered.

\section{A2. Area 1: The Universal Decision Making Process}

Decision making can be organized in the following 5 steps:

A2.1. Framing of the Decision or Defining a Decision Charter. The decision problem is defined, conditions and limits to the decision making are stated, preconditions, available information, affected people, anything that can help to make the decision is collected and put into the decision charter [1].

A2.2. Objectives are identified and a hierarchy of objectives is created. Means and ends are separated and tested for their usefulness [2].

A2.3. Creating Alternatives, Search for and identification of decision choices [3].

A2.4. Weighing and Choosing evaluates the alternatives to find the best alternative [4].

A2.5. Implementing and Monitoring realizes the chosen decision alternative and evaluates the outcome of the decision process and the decision [5].

\section{A3. Area 2: Circumstances of Decision Making}

For all decision making, the process defined above is used.

A3.1. Individual Decisions. The individual decision maker works through the process steps. To enhance the results, experts can be consulted to complement the available information, but the decision is made by the individual.

A3.1.1. Advantage of individual decision making: Quick results are possible.

A3.1.2. Disadvantage of individual decision making: It can be hard to find many alternatives, the decision is based on the limited views of one person, biases can negatively influence a decision [6].

A3.2. Group Decisions. A group of people makes the decision. In addition to the decision making process steps, the group has to be assembled and the work has to be planned and organized.

A3.2.1. Advantage of group decision making: A broad knowledge base is available and gives a stronger base for the decision making.

A3.2.2. Disadvantage of group decision making: It can take long until a group finally decides. Group think and group biases can lead to errors in decision making [7].

A3.3. Organizational Decisions. In corporate decisions, the leadership and management of the company usually has a larger view of the change processes related to implementing a decision. Corporate decisions do not always have to be made top down by the leaders and managers, they can also be delegated bottom up by empowering lower management. If the decision involves corporate changes though, the top leadership and company management as well as the affected stakeholders have to support the change to enhance the chance of its success.

Decisions can be made by individuals or in groups. Often there are specific decision rules in place, supported by corresponding decision tools. The evaluation of decision alternatives has to take the effects of implementation, change processes, and organizational culture into consideration. if several decisions are dependent on one another, the individual decision has to be made such that the over-all outcome is optimized or maximized [8].

\section{A4. Area 3: Influences to Consider}

The most common effects to be considered in decision making are:

- Bias [9];

- Stakeholders [10];

- Methods used in decision making, like applying brainstorming or decision trees. 
Besides these effects, decision makers have to remain on the outlook for irregularities in the decision making process. When the decision process either gets blocked and does not seem to progress any more, or if everything is going too smoothly, the process should be reviewed and the initially planned schedule of the decision making process steps has to be enforced or adapted.

\section{A5. Area 4: Examples of Good and Bad Decision Making}

There is ample literature available about cases of corporate decision making and examples of decision making can be found daily in the news. Besides looking at the outcomes of the decisions, the examples can be analyzed with the tools and knowledge from the first three areas:

- How was the decision making process followed?

- How was the decision making applied and organized?

- What side effects are visible?

\section{A6. Conclusion}

This short overview of decision making presents the framework of the content of the introductory course on decision making.

\section{References}

[1] M. Salzer. Framing a decision, [Online]. Available: http://www.saylor.org/site/wp-content/ uploads/2013/02/BUS208-8.1.6-Framing-a-Decision-FINAL.pdf

[2] B. Monger. Decision making - goals and objectives, May 29, 2011, [Online]. Available: https://smartamarketing.wordpress.com/2011/05/29/decision-making-goals-and-objectives/

[3] Decision Innovation. The innovate step - generating a robust set of decision alternatives, [Online]. Available: http:/www.decision-making-solutions.com/decision-alternatives.html

[4] M. K. Rebori. Effective problem-solving techniques for groups, [Online]. Available: http://www.unce.unr.edu/publications/files/cd/other/fs9726.pdf

[5] Study Guides and Strategies. Implementing decisions, [Online]. Available: http://www.studygs.net/problem/problemsolvingv3.htm

[6] MSG Experts. Individual decision making - pros and cons, [Online]. Available: http://managementstudyguide.com/individual-decision-making.htm

[7] T. Barnett. Group decision making, 2016, [Online]. Available: http://www.referenceforbusiness.com/management/Gr-Int/Group-Decision-Making.html

[8] MSG Experts. The process of corporate decision making, [Online]. Available: http://managementstudyguide.com/corporate-decision-making.htm

[9] J. Beshears and F. Gino. Identifying the biases behind your bad decisions, in Harvard Business Review, October 31, 2014, [Online]. Available: https:/hbr.org/2014/10/identifying-the-biases-behind-your-bad-decisions

[10]D. Fout. How do your stakeholders affect your decision making? September 14, 2011, [Online]. Available: http://www.aquilent.com/blog/2011/09/how-do-your-stakeholders-affect-your-decision-making/ 